\title{
Fatty acids and related lipid mediators in the regulation of cutaneous inflammation
}

DOI:

10.1042/BST20160469

\section{Document Version}

Accepted author manuscript

Link to publication record in Manchester Research Explorer

\section{Citation for published version (APA):}

Kiezel-Tsugunova, M., Kendall, A., \& Nicolaou, A. (2018). Fatty acids and related lipid mediators in the regulation of cutaneous inflammation. Biochemical Society. Transactions. https://doi.org/10.1042/BST20160469

\section{Published in:}

Biochemical Society. Transactions

\section{Citing this paper}

Please note that where the full-text provided on Manchester Research Explorer is the Author Accepted Manuscript or Proof version this may differ from the final Published version. If citing, it is advised that you check and use the publisher's definitive version.

\section{General rights}

Copyright and moral rights for the publications made accessible in the Research Explorer are retained by the authors and/or other copyright owners and it is a condition of accessing publications that users recognise and abide by the legal requirements associated with these rights.

\section{Takedown policy}

If you believe that this document breaches copyright please refer to the University of Manchester's Takedown Procedures [http://man.ac.uk/04Y6Bo] or contact uml.scholarlycommunications@manchester.ac.uk providing relevant details, so we can investigate your claim.

\section{OPEN ACCESS}




\section{Fatty acids and related lipid mediators in the regulation of cutaneous}

\section{inflammation}

Magdalena Kiezel-Tsugunova, Alexandra C Kendall, Anna Nicolaou*

Laboratory for Lipidomics and Lipid Biology, Division of Pharmacy and Optometry, School of Health Sciences, Faculty of Biology, Medicine and Health, University of Manchester, Manchester Academic Health Science Centre, Manchester M13 9PL, UK.

*Corresponding author: Prof A Nicolaou; email: anna.nicolaou@manchester.ac.uk. 


\section{ABSTRACT}

Human skin has a distinct profile of fatty acids and related bioactive lipid mediators that regulate many aspects of epidermal and dermal homeostasis, including immune and inflammatory reactions. Sebum lipids act as effective antimicrobial agents, shape immune cell communications and contribute to the epidermal lipidome. The essential fatty acid linoleic acid is crucial for the structure of the epidermal barrier, while polyunsaturated fatty acids act as precursors to eicosanoids, octadecanoids and docosanoids through cyclooxygenase, lipoxygenase and cytochrome P450 monooxygenase-mediated reactions, and endocannabinoids and $\mathrm{N}$-acyl ethanolamines. Cross-communication between these families of bioactive lipids suggests that their cutaneous activities should be considered as part of a wider metabolic network that can be targeted to maintain skin health, control inflammation and improve skin pathologies.

\section{ABBREVIATIONS}

2-AG: 2-arachidonoyl glycerol; AA: Arachidonic acid; AEA: Arachidonoyl ethanolamine; CB: Cannabinoid receptor; COX: Cyclooxygenase; CYP: Cytochrome P450; DHA: Docosahexaenoic acid; DHET: Dihydroxyeicosatrienoic acid; EET:Epoxyeicosatetrienoic acid; EGF: Epidermal growth factor; EPA: Eicosapentaenoic acid; EPEA: Eicosapentaenoyl ethanolamine; HDHA: Hydroxydocosahexaenoic acid; HEPE: Hydroxyeicosapentaenoic acid; HETE: Hydroxyeicosatetraenoic acid; HODE: Hydroxyoctadecadienoic acid; IL: Interleukin; LA: Linoleic acid; LOX: Lipoxygenase; LPS: Lipopolysaccharide; LT: Leukotriene; MUFA: Monounsaturated fatty acid; NAE: N-acyl ethanolamine; OA: Oleic acid; OEA: Oleoyl ethanolamine; PA: Palmitic acid; PEA: Palmitoyl ethanolamine; PG: Prostaglandin; PUFA: Polyunsaturated fatty acid; SFA: Saturated fatty acid; SPM: specialised pro-resolving mediator; UVR: Ultraviolet radiation. 


\section{INTRODUCTION}

Fatty acids have long been recognised for their importance in skin health, and essential fatty acid deficiencies result in fatal epidermal barrier failure, characterised by desquamation and skin lesions $(1,2)$. Altering the cutaneous fatty acid profile through diet or nutritional supplementation has been reported to ameliorate inflammatory conditions [reviewed in (36)]. As well as having direct effects on signalling pathways, gene transcription, inflammatory and immune responses, many of the fatty acid-mediated bioactivities are attributed, at least in part, to the formation of bioactive derivatives. These lipid mediators are produced via sequential enzymatic reactions that typically start with the liberation of the relevant fatty acid precursor from membrane phospholipids, following the action of inflammatory or other stimuli that activate the relevant phospholipases (7-9). Once cleaved from the cellular membranes, free fatty acids can be converted into an array of bioactive mediators following the action of prostaglandin-endoperoxide synthases (cyclooxygenases; COX), lipoxygenases (LOX) and cytochrome P450 monooxygenases (CYP), as well as transcellular and non-enzymatic reactions. Figure $\mathbf{1}$ shows a diagrammatic outline of the main biochemical reactions mediating the biotransformation of the key polyunsaturated fatty acid (PUFA) arachidonic acid (AA; C20:4n-6). The metabolism of various cutaneous PUFA occurs in a similar way, and results in an array of eicosanoids, docosanoids, octadecanoids, endocannabinoids and $\mathrm{N}$-acyl ethanolamines (NAE), that have all been implicated in numerous aspects of cutaneous inflammation $(3,5)$. This review article aims to give an overview of the most important fatty acids that are found in human skin, discuss their properties, and introduce the biochemical pathways leading to the formation of bioactive lipid mediators involved in skin cell biology. A detailed appreciation of the profiles and balance of cutaneous fatty acids and related metabolites is important as this system can be targeted to maintain skin health, regulate inflammation, and improve skin pathologies. 


\section{CUTANEOUS FATTY ACIDS}

\subsection{SEBUM FATTY ACIDS}

Human sebum has a unique fatty acid profile that contains the sebum-characteristic sapienic acid (C16:1n-10), as well as palmitic acid (PA; C16:0), palmitoleic acid (C16:1n-7), and oleic acid (OA; C18:1n-9) (10-12). Importantly, sebum-derived fatty acids have been shown to be effective antimicrobial agents for bacteria such as Porphyromonas gingivalis, Staphylococcus aureus and Staphylococcus epidermidis, and play an active role in shaping the cutaneous microbiome (11-16). They are also actively involved in epidermal homeostasis and immune cell communications. It has been shown that OA can alter intracellular calcium in normal human keratinocytes and murine skin, leading to hyperproliferation and increased trans-epidermal water loss, while palmitoleic acid can cause keratinocyte hyperplasia in mouse skin $(17,18)$. Overall, sebum fatty acids contribute significantly to skin health and epidermal defence functions $(16,19)$, directly affecting epidermal keratinocytes, informing the cutaneous immune barrier, and protecting the surface of the skin from pathogenic microorganisms.

\subsection{FATTY ACIDS IN EPIDERMIS AND DERMIS}

Cutaneous fatty acids found in the epidermis and dermis are key determinants of skin health. The epidermis is the outermost skin layer and comprises a basal layer of proliferating keratinocytes, which switch to differentiate and migrate upwards to form multiple stratified layers of denucleated cells at the surface (19). The most abundant fatty acids in this layer are saturated fatty acids (SFA) i.e. PA and stearic acid, and monounsaturated fatty acids (MUFA) such as OA ( 23\% each) (20). The dermis contains high levels of unsaturated fatty acids, mostly OA ( 45\%), as well as the SFA PA ( 20\%) (20). The ratio between SFA and MUFA represents the activity of $\Delta 9$ desaturase, an enzyme important for skin health: inhibition of $\Delta 9$ desaturase was shown to reduce proliferation of dermal fibroblasts and disturb the cellular response to growth factors, whilst deletion of the $\Delta 9$ desaturase gene in 
an animal model resulted in a ulcerative dermatitis, dry, flaky skin and severe alopecia (2123).

Polyunsaturated fatty acids (PUFA) are found at lower levels than SFA or MUFA, e.g. linoleic acid (LA; C18:2n-6) and AA comprise approximately $9-10 \%$ and $2-3 \%$ of the epidermal fatty acids, respectively. However, PUFA are very important for skin health [reviewed in (20)]. Linoleic acid is an essential fatty acid, an integral component of acylceramides, and insufficient levels result in impaired formation of the epidermal permeability barrier $(24,25)$. Indeed, genetic abnormalities in elongase enzymes (for example ELOV4 deficiency), render the skin unable to produce long chain fatty acids, and the barrier fails due to an absence of acylceramides (26). Additionally, the epidermis relies on the dermis and systemic supplementation to provide long chain PUFA such as AA, eicosapentaenoic acid (EPA; C20:5n-3) and docosahexaenoic acid (DHA; C22:6n-3), as it lacks the necessary $\Delta 5$ and $\Delta 6$ desaturases to form these long chain PUFA from C18 fatty acid precursors (27). Thus the cutaneous profile of these fatty acids is greatly influenced by diet, and responds to nutritional supplementation $(4,5,28)$. Animal and clinical studies, as well as work with preclinical models, have shown that PUFA supplementation can confer photoprotection, improve wound healing and reduce inflammatory markers $(4,29,30)$. Although the detailed molecular mechanisms of how fatty acids influence skin health are not always understood, often their effects can be attributed to formation of bioactive metabolites, as discussed below.

\section{FATTY ACID-DERIVED LIPID MEDIATORS}

\subsection{PROSTANOIDS}

The family of prostanoids includes various prostaglandins (PG), thromboxanes (TX) and prostacyclin $\left(\mathrm{PGl}_{2}\right)$, all formed from 20-carbon PUFA precursors (i.e. AA, dihomo-gamma linolenic acid (DGLA; C18:3n-6) and EPA), through the activities of constitutive COX-1 and/or inducible COX-2, and terminal prostanoid synthases (Figure 1). The bioactivities of 
prostanoids are mediated though a series of $G$ protein coupled receptors that have been identified in many cell types, including skin cells [reviewed in $(3,5,7)]$.

Keratinocytes and fibroblasts, as well as skin-resident immune cells, produce a number of prostanoids including $\mathrm{PGE}_{2}, \mathrm{PGE}_{1}, \mathrm{PGE}_{3}, \mathrm{PGD}_{2}, \mathrm{PGF}_{2 \alpha}, \mathrm{PGI}_{2}$, and $\mathrm{TXB}_{2}$ (31-33). One of the best studied species is $\mathrm{PGE}_{2}$, which regulates keratinocyte and fibroblast growth and proliferation through production of growth factors and cytokines, including fibroblast growth factor, epidermal growth factor (EGF), tumour necrosis factor- $\alpha$, interleukin (IL) -1, IL-6 and IL-8 (34-39). PGE 2 also acts as a potent immunomodulatory stimulus, triggering recruitment of T lymphocytes and maturation of dendritic cells, both important for skin immunity (40-42). These changes are associated with vasodilation and further recruitment of immune cells, as demonstrated by the increased accumulation of neutrophils and oedema in rodent skin following a local injection of $\mathrm{PGE}_{1}$ and $\mathrm{PGE}_{2}(43,44)$. Conversely, $\mathrm{PGE}_{3}$ was not mitogenic in murine epidermal cultures or a dermal fibroblast cell line, and it has been suggested to play an anti-inflammatory role (45-47).

$\mathrm{PGD}_{2}$ can also stimulate T-cell and eosinophil migration (48). In skin, it is produced mainly by Langerhans cells and dermal mast cells, and high levels of $\mathrm{PGD}_{2}$ have been linked to hair loss and androgenetic alopecia (49). The inhibition of hair growth involves a potent apoptotic action of $\mathrm{PGD}_{2}$ on follicular keratinocytes, although it has also been shown that $\mathrm{PGD}_{2}$ may also act as an anti-inflammatory mediator, depending on the cell type and time of its production (50).

Multiple studies have shown increased production of cutaneous prostanoids following the upregulation of COX-2 in response to inflammatory stimuli, as observed in the sunburn reaction and wound healing $(33,51,52)$. Interestingly, COX-2 inhibitors were found to cause a significant delay to wound healing, with wounds showing significant reduction in $\mathrm{PGE}_{2}$ levels, epidermal proliferation, angiogenesis and extracellular matrix $(53,54)$. However, mice showed accelerated wound healing when catabolism of $\mathrm{PGE}_{2}$ was inhibited $(55,56)$. This 
finding highlights the role of skin prostaglandins in regulating the early phases of inflammation, which are crucial for efficient resolution and tissue remodelling. Non-steroidal anti-inflammatory drugs inhibit COX-1 and -2 activity, and therefore prostanoid production, which may reduce skin inflammation. However free fatty acids are then metabolised through other enzyme pathways. Indeed, when cutaneous COX-derived prostaglandin production was blocked by indomethacin, LOX metabolism dominated and an increase in 12hydroxyeicosatetraenoic acid (HETE) was observed, so although erythema was reduced, there was a greater inflammatory infiltrate in the skin (57). Interestingly, $\mathrm{PGE}_{2}$ has recently been shown to mediate a phase of post-inflammatory immune-suppression, believed to be important for prevention of an autoimmune response, highlighting its importance past the initial inflammatory phase (58).

\subsection{HYDROXY FATTY ACIDS}

Lipoxygenases (LOX) produce a series of hydroxy fatty acids and leukotrienes (LT) $(59,60)$. Human and animal skin express a number of LOX isoforms, e.g. 5-, 8-, 12- and 15-LOX, that can utilise a range of fatty acid substrates, including AA, LA, EPA, DGLA and DHA [reviewed in $(3,5,7)$ ] (Figure 1). The $12 R$-LOX is unique to mammalian skin cells and has been purported to be involved in cutaneous inflammation, given observations of $12 R$-HETE in psoriasis skin. Its main role, however, is believed to be linked to the formation of the epidermal lipid barrier, in conjunction with the epidermis-type eLOX-3. These two enzymes perform consecutive oxidisations of the linoleic acid in acylceramides, enabling its linkage to cornified envelope proteins, which is crucial for an effective epidermal barrier (60-63). Indeed, congenital ichthyosis has been linked to mutations in $12 R \operatorname{LOX}$ and eLOX-3 $(64,65)$. LOX reactions are also involved in the transcellular metabolism of PUFA to generate lipoxins from $A A$, resolvins and protectins from EPA and DHA, and maresins from DHA, collectively known as specialised pro-resolving mediators (SPMs) for their anti-inflammatory functions (66). Although a number of their hydroxy fatty acid precursors have been found in skin, before and after PUFA supplementation, the SPMs themselves have not been identified in 
skin to-date, and their importance in cutaneous health and disease remains unclear $(29,67$, 68).

Linoleic acid-derived hydroxyoctadecadienoic acids (HODE) are the most abundant hydroxy fatty acids found in human skin (20). Both 9- and 13-HODE are potent chemotactic agents, and cause increased infiltration and migration of neutrophils and macrophages, as well as regulating the proliferation and differentiation of epidermal keratinocytes (69-72). Recently, HODE have been considered as important mediators in inflammatory pain, although evidence for their role in cutaneous pain is limited $(73,74)$.

Leukotrienes (LT) are 5-LOX derivatives of AA with potent chemotactic properties, and induce neutrophil infiltration in inflamed skin. However, the cutaneous activity of 5-LOX is relatively low, and increased formation of LT has been attributed to infiltrating immune cells and not resident skin cells $(75,76)$. 12-HETE and 15-HETE are the main LOX-derived products of AA in skin (20). 12-HETE is considered pro-inflammatory, and has been associated with increased infiltration of leukocytes $(57,77,78) .15$-HETE has been shown to decrease levels of $\mathrm{LTB}_{4}$ and 12-HETE, and stimulate the remodelling of injury sites and production of EGF in endothelial cells, a property important in the later stages of inflammation (79-82). Both 12-LOX and 15-LOX protein expression has been found upregulated in human skin following exposure to UVR, with concomitant increases in 12and 15-HETE (33), while increased 15-LOX gene expression in the human skin has been associated with a reduction of pro-inflammatory IL-6 and TNFa, epidermal thickness and epidermal cell migration (83). Interestingly, a study on mice lacking the 12/15LOX gene showed a reduced number of mesenchymal stem cells with disturbed kinetics in the wounded dermis, which has implications for tissue remodelling (84). Additionally, the 12-LOX DHA product, 14-HDHA improved all stages of the wound healing process in mice, via enhanced reepithelization, granulation and angiogenesis (85). Hence, these findings confirm a strong involvement of LOX-derived PUFA mediators in sustaining the later stages of inflammation, when COX-mediated production of prostaglandins has decreased (33). 


\subsection{EPOXY FATTY ACIDS}

The cytochrome P450 (CYP) isozymes CYP2C and CYP2J are epoxygenases that mediate the production of epoxyeicosatrienoic acids (EET) from AA (Figure 1). These epoxides are rapidly transformed by the soluble epoxide hydrolase $(\mathrm{sEH})$ to dihydroeicosatetraenoic acids (DHET) that exhibit much reduced bioactivities. Furthermore, CYP-mediated oxidations can produce a range of HETE similar to the ones formed by LOX. Other PUFA substrates for CYP reactions include LA, EPA and DHA (86-88).

While the role of DHET in skin inflammation is unclear, cutaneous functions of EET are emerging. Increasing endogenous levels of EET via inhibition of $s E H$ improved vascularization in an engineered skin substitute (89). Additionally, topical application of EET accelerated epithelialization in the hairless mouse, while CYP inhibitors significantly delayed wound closure $(90,91)$. Analysis of individual EET has revealed that 11,12 EET increases angiogenesis and improves wound healing in diabetic mice, while 14,15 EET is directly involved in epidermal barrier function through regulation of involucrin and promotion of the cornification of human and murine keratinocytes $(92,93)$. The non-epoxy CYP product 20HETE appears to have a role in angiogenesis, as it leads to increased proliferation and migration of endothelial cells $(94,95)$. Despite a limited understanding of the role of CYP reactions and resulting epoxy fatty acids in skin health, these compounds appear to be important during later stages of inflammation and wound healing, and further research to elucidate EET and DHET function in skin is required (96-98).

\subsection{ENDOCANNABINOIDS AND N-ACYL ETHANOLAMINES}

Human skin produces the classic endocannabinoids arachidonoyl ethanolamine (anandamide; AEA) and 2-arachidonoyl glycerol (2-AG)), as well as a range of $\mathrm{N}$-acyl ethanolamines (NAE) (20) (Figure 1). AEA and 2-AG are known ligands for the cannabinoid receptors $\mathrm{CB} 1$ and $\mathrm{CB} 2$, the expression of which has been reported in the epidermis, dermoepidermal junction and dermis $(20,99)$. AEA and 2-AG derive from phospholipid-esterified 
arachidonic acid, and can be further metabolised by COX, LOX and CYP enzymes, however the prevalence of these species in human skin has not been confirmed (9). Many of the fatty acid-derived NAE present very low or no affinity to $\mathrm{CB} 1$ or $\mathrm{CB} 2$, and are believed to act through other receptors such as vanilloid receptor 1 (TRPV1) and PPARa $(100,101)$.

Endocannabinoids and NAE are involved in various cutaneous functions, including keratinocyte differentiation $(102,103)$. AEA inhibits the proliferation of human epidermal keratinocytes and dermal fibroblasts via induction of apoptosis (103, 104). This apoptotic function of $A E A$ was also observed in human sebocytes, where both $A E A$ and 2-AG stimulated differentiation, maturation and lipogenesis via CB2-mediated signalling (105, 106). Furthermore, AEA limits excessive mast cell activation in hair follicles, highlighting its function in the regulation of dermal inflammation (107). Palmitoyl ethanolamine (PEA) and oleoyl ethanolamine (OEA) have anti-inflammatory and analgesic effects, and PEA has been shown to reduce itching in a murine allergic dermatitis model, while linoleoyl ethanolamine (LEA) reduced lipopolysaccharide (LPS)-induced inflammation in macrophages, thereby improving contact dermatitis (108-111). The n-3 PUFA-derived eicosapentaenoyl ethanolamine (EPEA) and docosahexaenoyl ethanolamine (DHEA) have been shown to mediate anti-inflammatory protective mechanisms and reduction of itching and pain, suggesting a potentially important role in skin (112-114).

Endocannabinoids and NAEs may also serve as immunomodulatory mediators in the skin, and have been found to be upregulated during various types of skin inflammation $(99,115)$. AEA and 2-AG levels were increased after UVR treatment of HaCaT keratinocytes (116), while in study involving different keratinocyte and fibroblast cell lines, $A E A, 2-A G$ and $C B 1$ and CB2 expression were found to decrease following UVR irradiation $(117,118)$. A clinical study (119) reported increased 2-AG but stable levels of AEA, OEA and PEA in the serum of human volunteers subjected to a repetitive cutaneous exposure to simulated solar UVR (119). Similarly, the skin of human volunteers irradiated with low-dose UVR did not show any 
changes in levels of endocannabinoids and NAE species, although there was an increase of stearoyl ethanolamine, LEA, OEA and PEA following sodium lauryl sulfate application (120) . Mustard vesicants also increased levels of $A E A$ and 2-AG, and increased expression of $C B$ receptors, in murine skin in vivo, although only several days after stimulation (121).

Overall, it is believed that endocannabinoids and NAE may act to quench inflammation, and their production may prevent an excessive inflammatory response in the skin. Upregulation of $\mathrm{CB} 1 / \mathrm{CB} 2$ receptor expression was observed in fibroblasts and macrophage-like cells during wound healing in rats (104), while 2-AG and CB1 activation are associated with reduced immune infiltration, scarring and accelerated wound closure in epithelial cells. However, CB1 activation in the dermis slowed wound healing, suggesting different roles for endocannabinoids in the different skin compartments $(104,122)$.

\section{CONCLUSION}

Fatty acids are crucial for skin health, as they contribute to the structural and functional integrity of the epidermis. Additionally, their metabolism into a range of bioactive mediators that regulate various aspects of epidermal and dermal homeostasis, including immune and inflammatory reactions, shows their importance for cutaneous health and disease. The availability of precursor fatty acids, coupled to the expression and activity of lipid metabolising enzymes, determines the profile of cutaneous lipid mediators. COX-derived prostaglandins and LOX-derived hydroxy fatty acids respond to most inflammatory stimuli; the properties of these mediators are continually being elucidated. CYP-derived lipid mediators have not been extensively studied in the skin, but there is evidence supporting their involvement in tissue remodelling. Finally, endocannabinoids and NAEs appear to support homeostasis and transcellular signalling during cutaneous inflammation, and may prevent excessive immune responses. The cross-communication between these families of fatty acid-derived lipids suggests that their properties should not be studied in isolation, and 
their prevalence should be considered as part of a wider metabolic network that regulates cutaneous reactions.

ACKNOWLEDGMENTS: The support of NIHR Manchester Biomedical Research Centre and MRC (MC_PC_15058) is gratefully acknowledged.

DECLARATION OF INTEREST: The authors have no interests to declare

FUNDING INFORMATION: AN is supported by the NIHR Manchester Biomedical Research Centre as a Dermatology Theme Key Researcher. ACK was supported by the Medical Research Council (grant MC_PC_15058).

AUTHOR CONTRIBUTION STATEMENT: All authors contributed equally to the work. 


\section{REFERENCES}

1. Burr GO, Burr MM. A new deficiency disease produced by the rigid exclusion of fat from the diet. J Biol Chem. 1929;82:345-67.

2. Burr GO, Burr MM. On the nature and role of the fatty acids essential in nutrition. Journal of Biological Chemistry. 1930;86(2):587-621.

3. Kendall AC, Nicolaou A. Bioactive lipid mediators in skin inflammation and immunity. Prog Lipid Res. 2013;52(1):141-64.

4. Pilkington SM, Watson RE, Nicolaou A, Rhodes LE. Omega-3 polyunsaturated fatty acids: photoprotective macronutrients. Exp Dermatol. 2011;20(7):537-43.

5. Nicolaou A. Eicosanoids in skin inflammation. Prostaglandins Leukot Essent Fatty Acids. 2013;88(1):131-8.

6. Nicolaou A, Pilkington SM, Rhodes LE. Ultraviolet-radiation induced skin inflammation: dissecting the role of bioactive lipids. Chem Phys Lipids. 2011;164(6):535-43. Epub 2011/04/29.

7. Massey KA, Nicolaou A. Lipidomics of polyunsaturated-fatty-acid-derived oxygenated metabolites. Biochem Soc Trans. 2011;39(5):1240-6. Epub 2011/09/23.

8. Astarita G, Kendall AC, Dennis EA, Nicolaou A. Targeted lipidomic strategies for oxygenated metabolites of polyunsaturated fatty acids. Biochim Biophys Acta. 2015;1851(4):456-68.

9. Urquhart P, Nicolaou A, Woodward DF. Endocannabinoids and their oxygenation by cyclo-oxygenases, lipoxygenases and other oxygenases. Biochim Biophys Acta. 2015;1851(4):366-76. Epub 2014/12/30.

10. Zouboulis CC, Picardo M, Ju Q, Kurokawa I, Torocsik D, Biro T, et al. Beyond acne: Current aspects of sebaceous gland biology and function. Rev Endocr Metab Disord. 2016;17(3):319-34. Epub 2016/10/12.

11. Wille JJ, Kydonieus A. Palmitoleic acid isomer (C16:1delta6) in human skin sebum is effective against gram-positive bacteria. Skin Pharmacol Appl Skin Physiol. 2003;16(3):17687. Epub 2003/04/05.

12. Desbois AP, Lawlor KC. Antibacterial activity of long-chain polyunsaturated fatty acids against Propionibacterium acnes and Staphylococcus aureus. Mar Drugs. 2013;11(11):4544-57.

13. Moran JC, Alorabi JA, Horsburgh MJ. Comparative transcriptomics reveals discrete survival responses of $\mathrm{S}$. aureus and $\mathrm{S}$. epidermidis to sapienic acid. Front Microbiol. 2017;8:33.

14. Fischer CL, Dawson DV, Blanchette DR, Drake DR, Wertz PW, Brogden KA. Protein analysis of sapienic acid-treated Porphyromonas gingivalis suggests differential regulation of multiple metabolic pathways. J Bacteriol. 2015;198(1):157-67.

15. Nakatsuji T, Kao MC, Zhang L, Zouboulis CC, Gallo RL, Huang CM. Sebum free fatty acids enhance the innate immune defense of human sebocytes by upregulating betadefensin-2 expression. J Invest Dermatol. 2010;130(4):985-94. Epub 2009/12/25.

16. Drake DR, Brogden KA, Dawson DV, Wertz PW. Thematic review series: skin lipids. Antimicrobial lipids at the skin surface. J Lipid Res. 2008;49(1):4-11. Epub 2007/10/02.

17. Katsuta $Y$, lida T, Hasegawa K, Inomata S, Denda M. Function of oleic acid on epidermal barrier and calcium influx into keratinocytes is associated with N-methyl Daspartate-type glutamate receptors. Br J Dermatol. 2009;160(1):69-74.

18. Katsuta $Y$, lida $T$, Inomata S, Denda M. Unsaturated fatty acids induce calcium influx into keratinocytes and cause abnormal differentiation of epidermis. J Invest Dermatol. 2005;124(5):1008-13.

19. Elias PM, Choi EH. Interactions among stratum corneum defensive functions. Exp Dermatol. 2005;14(10):719-26. Epub 2005/09/24.

20. Kendall AC, Pilkington SM, Massey KA, Sassano G, Rhodes LE, Nicolaou A. Distribution of bioactive lipid mediators in human skin. J Invest Dermatol. 2015;135(6):151020. 
21. Coomans de Brachene A, Dif N, de Rocca Serra A, Bonnineau C, Velghe Al, Larondelle $\mathrm{Y}$, et al. PDGF-induced fibroblast growth requires monounsaturated fatty acid production by stearoyl-CoA desaturase. FEBS Open Bio. 2017;7(3):414-23.

22. Krugner-Higby L, Brown R, Rassette M, Behr M, Okwumabua O, Cook M, et al. Ulcerative dermatitis in C57BL/6 mice lacking stearoyl CoA desaturase 1. Comp Med. 2012;62(4):257-63.

23. Sampath $\mathrm{H}$, Ntambi JM. Role of stearoyl-CoA desaturase-1 in skin integrity and whole body energy balance. J Biol Chem. 2014;289(5):2482-8.

24. Uchida Y. Ceramide signaling in mammalian epidermis. Biochim Biophys Acta. 2014;1841(3):453-62.

25. Kendall AC, Kiezel-Tsugunova M, Brownbridge LC, Harwood JL, Nicolaou A. Lipid functions in skin: Differential effects of n-3 polyunsaturated fatty acids on cutaneous ceramides, in a human skin organ culture model. Biochim Biophys Acta. 2017;1859(9 Pt B):1679-89.

26. Vasireddy V, Uchida Y, Salem JN, Kim SY, Mandal MNA, Reddy GB, et al. Loss of functional ELOVL4 depletes very long-chain fatty acids $(\geq \mathrm{C} 28)$ and the unique $\omega-O$ acylceramides in skin leading to neonatal death. Human Molecular Genetics. 2007;16(5):471-82.

27. Chapkin RS, Ziboh VA. Inability of skin enzyme preparations to biosynthesize arachidonic acid from linoleic acid. Biochem Biophys Res Commun. 1984;124(3):784-92. Epub 1984/11/14.

28. Pilkington SM, Rhodes LE, Al-Aasswad NM, Massey KA, Nicolaou A. Impact of EPA ingestion on COX- and LOX-mediated eicosanoid synthesis in skin with and without a proinflammatory UVR challenge--report of a randomised controlled study in humans. Mol Nutr Food Res. 2014;58(3):580-90.

29. McDaniel JC, Massey K, Nicolaou A. Fish oil supplementation alters levels of lipid mediators of inflammation in microenvironment of acute human wounds. Wound Repair Regen. 2011;19(2):189-200.

30. McCusker MM, Grant-Kels JM. Healing fats of the skin: the structural and immunologic roles of the omega- 6 and omega-3 fatty acids. Clin Dermatol. 2010;28(4):44051. Epub 2010/07/14.

31. Ziboh VA. Prostaglandins, leukotrienes, and hydroxy fatty acids in epidermis. Semin Dermatol. 1992;11(2):114-20.

32. Sugimoto M, Arai I, Futaki N, Hashimoto Y, Honma Y, Nakaike S. Role of COX-1 and COX-2 on skin PGs biosynthesis by mechanical scratching in mice. Prostaglandins Leukot Essent Fatty Acids. 2006;75(1):1-8. Epub 2006/07/04.

33. Rhodes LE, Gledhill K, Masoodi M, Haylett AK, Brownrigg M, Thody AJ, et al. The sunburn response in human skin is characterized by sequential eicosanoid profiles that may mediate its early and late phases. FASEB J. 2009;23(11):3947-56.

34. Arai KY, Fujioka A, Okamura R, Nishiyama T. Stimulatory effect of fibroblast-derived prostaglandin $E(2)$ on keratinocyte stratification in the skin equivalent. Wound Repair Regen. 2014;22(6):701-11.

35. Sato T, Kirimura Y, Mori Y. The co-culture of dermal fibroblasts with human epidermal keratinocytes induces increased prostaglandin E2 production and cyclooxygenase 2 activity in fibroblasts. J Invest Dermatol. 1997;109(3):334-9.

36. Ansari KM, Rundhaug JE, Fischer SM. Multiple signaling pathways are responsible for prostaglandin E2-induced murine keratinocyte proliferation. Mol Cancer Res. 2008;6(6):1003-16.

37. Iwanaga K, Okada M, Murata T, Hori M, Ozaki H. Prostaglandin E2 promotes woundinduced migration of intestinal subepithelial myofibroblasts via EP2, EP3, and EP4 prostanoid receptor activation. J Pharmacol Exp Ther. 2012;340(3):604-11.

38. Storey A, McArdle F, Friedmann PS, Jackson MJ, Rhodes LE. Eicosapentaenoic acid and docosahexaenoic acid reduce UVB- and TNF-alpha-induced IL-8 secretion in keratinocytes and UVB-induced IL-8 in fibroblasts. J Invest Dermatol. 2005;124(1):248-55. 
39. Loftin CD, Eling TE. Prostaglandin synthase 2 expression in epidermal growth factordependent proliferation of mouse keratinocytes. Arch Biochem Biophys. 1996;330(2):419-29. 40. Mcllroy A, Caron G, Blanchard S, Fremaux I, Duluc D, Delneste Y, et al. Histamine and prostaglandin $\mathrm{E}$ up-regulate the production of Th2-attracting chemokines (CCL17 and CCL22) and down-regulate IFN-gamma-induced CXCL10 production by immature human dendritic cells. Immunology. 2006;117(4):507-16.

41. Poloso NJ, Urquhart P, Nicolaou A, Wang J, Woodward DF. PGE2 differentially regulates monocyte-derived dendritic cell cytokine responses depending on receptor usage (EP2/EP4). Mol Immunol. 2013;54(3):284-95.

42. Nicolaou A, Mauro C, Urquhart P, Marelli-Berg F. Polyunsaturated fatty acid-derived lipid mediators and T cell function. Front Immunol. 2014;5:75.

43. Teixeira MM, Williams TJ, Hellewell PG. E-type prostaglandins enhance local oedema formation and neutrophil accumulation but suppress eosinophil accumulation in guinea-pig skin. Br J Pharmacol. 1993;110(1):416-22.

44. Hasegawa $\mathrm{H}$, Ichioka $\mathrm{S}$. Effects of lipo-prostaglandin $\mathrm{E} 1$ on wound bed microcirculation. J Wound Care. 2015;24(7):293-4, 6, 8-9.

45. Bagga D, Wang L, Farias-Eisner R, Glaspy JA, Reddy ST. Differential effects of prostaglandin derived from omega- 6 and omega-3 polyunsaturated fatty acids on COX-2 expression and IL-6 secretion. Proc Natl Acad Sci U S A. 2003;100(4):1751-6.

46. Belury MA, Patrick KE, Locniskar M, Fischer SM. Eicosapentaenoic and arachidonic acid: comparison of metabolism and activity in murine epidermal cells. Lipids. 1989;24(5):423-9.

47. Shapiro AC, Wu D, Meydani SN. Eicosanoids derived from arachidonic and eicosapentaenoic acids inhibit T cell proliferative response. Prostaglandins. 1993;45(3):22940.

48. Kataoka N, Satoh T, Hirai A, Saeki K, Yokozeki H. Indomethacin inhibits eosinophil migration to prostaglandin D2 : therapeutic potential of CRTH2 desensitization for eosinophilic pustular folliculitis. Immunology. 2013;140(1):78-86.

49. Garza LA, Liu Y, Yang Z, Alagesan B, Lawson JA, Norberg SM, et al. Prostaglandin D2 inhibits hair growth and is elevated in bald scalp of men with androgenetic alopecia. Sci Transl Med. 2012;4(126):126ra34.

50. Sarashina H, Tsubosaka Y, Omori K, Aritake K, Nakagawa T, Hori M, et al. Opposing immunomodulatory roles of prostaglandin D2 during the progression of skin inflammation. $J$ Immunol. 2014;192(1):459-65.

51. Buckman SY, Gresham A, Hale P, Hruza G, Anast J, Masferrer J, et al. COX-2 expression is induced by UVB exposure in human skin: implications for the development of skin cancer. Carcinogenesis. 1998;19(5):723-9. Epub 1998/07/11.

52. Kapoor M, Kojima F, Yang L, Crofford LJ. Sequential induction of pro- and antiinflammatory prostaglandins and peroxisome proliferators-activated receptor-gamma during normal wound healing: a time course study. Prostaglandins Leukot Essent Fatty Acids. 2007;76(2):103-12.

53. Fairweather M, Heit YI, Buie J, Rosenberg LM, Briggs A, Orgill DP, et al. Celecoxib inhibits early cutaneous wound healing. J Surg Res. 2015;194(2):717-24.

54. Goren I, Lee SY, Maucher D, Nusing R, Schlich T, Pfeilschifter J, et al. Inhibition of cyclooxygenase-1 and -2 activity in keratinocytes inhibits PGE2 formation and impairs vascular endothelial growth factor release and neovascularisation in skin wounds. Int Wound J. 2017;14(1):53-63.

55. Seo SY, Han SI, Bae CS, Cho H, Lim SC. Effect of 15-hydroxyprostaglandin dehydrogenase inhibitor on wound healing. Prostaglandins Leukot Essent Fatty Acids. 2015;97:35-41.

56. Choi D, Piao YL, Wu Y, Cho $\mathrm{H}$. Control of the intracellular levels of prostaglandin $E(2)$ through inhibition of the 15-hydroxyprostaglandin dehydrogenase for wound healing. Bioorg Med Chem. 2013;21(15):4477-84. 
57. Pilkington SM, Murphy SA, Kudva S, Nicolaou A, Rhodes LE. COX inhibition reduces vasodilator PGE2 but is shown to increase levels of chemoattractant 12-HETE in vivo in human sunburn. Exp Dermatol. 2015;24(10):790-1.

58. Newson J, Motwani MP, Kendall AC, Nicolaou A, Muccioli GG, Alhouayek M, et al. Inflammatory resolution triggers a prolonged phase of immune suppression through COX1/mPGES-1-derived prostaglandin E2. Cell Rep. 2017;20(13):3162-75.

59. Brash AR. Lipoxygenases: occurrence, functions, catalysis, and acquisition of substrate. J Biol Chem. 1999;274(34):23679-82. Epub 1999/08/14.

60. Kuhn H, O'Donnell VB. Inflammation and immune regulation by $12 / 15$-lipoxygenases. Prog Lipid Res. 2006;45(4):334-56.

61. Boeglin WE, Kim RB, Brash AR. A 12R-lipoxygenase in human skin: mechanistic evidence, molecular cloning, and expression. Proc Natl Acad Sci U S A. 1998;95(12):67449. Epub 1998/06/17.

62. Zheng Y, Yin H, Boeglin WE, Elias PM, Crumrine D, Beier DR, et al. Lipoxygenases mediate the effect of essential fatty acid in skin barrier formation: a proposed role in releasing omega-hydroxyceramide for construction of the corneocyte lipid envelope. J Biol Chem. $2011 ; 286(27): 24046-56$.

63. Krieg $P$, Fürstenberger $G$. The role of lipoxygenases in epidermis. Biochimica et Biophysica Acta (BBA) - Molecular and Cell Biology of Lipids. 2014;1841(3):390-400.

64. Eckl K-M, Krieg $P$, Küster W, Traupe $H$, André F, Wittstruck N, et al. Mutation spectrum and functional analysis of epidermis-type lipoxygenases in patients with autosomal recessive congenital ichthyosis. Human Mutation. 2005;26(4):351-61.

65. Jobard F, Lefèvre C, Karaduman A, Blanchet-Bardon C, Emre S, Weissenbach J, et al. Lipoxygenase-3 (ALOXE3) and 12(R)-lipoxygenase (ALOX12B) are mutated in nonbullous congenital ichthyosiform erythroderma (NCIE) linked to chromosome 17p13.1. Human Molecular Genetics. 2002;11(1):107-13.

66. Serhan CN, Chiang N, Van Dyke TE. Resolving inflammation: dual anti-inflammatory and pro-resolution lipid mediators. Nat Rev Immunol. 2008;8(5):349-61. Epub 2008/04/26.

67. Nicolaou A, Masoodi M, Gledhill K, Haylett AK, Thody AJ, Tobin DJ, et al. The eicosanoid response to high dose UVR exposure of individuals prone and resistant to sunburn. Photochem Photobiol Sci. 2012. Epub 2011/12/17.

68. Pilkington SM, Rhodes LE, Al-Aasswad NM, Massey KA, Nicolaou A. Impact of EPA ingestion on COX- and LOX-mediated eicosanoid synthesis in skin with and without a proinflammatory UVR challenge - Report of a randomised controlled study in humans. Mol Nutr Food Res. 2013. Epub 2013/12/07.

69. Moch D, Schewe T, Kuhn H, Schmidt D, Buntrock $P$. The linoleic acid metabolite 9DS-hydroxy-10,12(E,Z)-octadecadienoic acid is a strong proinflammatory mediator in an experimental wound healing model of the rat. Biomed Biochim Acta. 1990;49(4):201-7.

70. Henricks PA, Engels F, van der Vliet H, Nijkamp FP. 9- and 13-hydroxy-linoleic acid possess chemotactic activity for bovine and human polymorphonuclear leukocytes. Prostaglandins. 1991;41(1):21-7.

71. Miller CC, Ziboh VA. Induction of epidermal hyperproliferation by topical $n-3$ polyunsaturated fatty acids on guinea pig skin linked to decreased levels of 13hydroxyoctadecadienoic acid (13-hode). J Invest Dermatol. 1990;94(3):353-8. Epub 1990/03/01.

72. Ogawa E, Owada Y, Ikawa S, Adachi Y, Egawa T, Nemoto K, et al. Epidermal FABP (FABP5) regulates keratinocyte differentiation by $13(\mathrm{~S})$-HODE-mediated activation of the NF-kappaB signaling pathway. J Invest Dermatol. 2011;131(3):604-12.

73. Ruparel S, Green D, Chen P, Hargreaves KM. The cytochrome P450 inhibitor, ketoconazole, inhibits oxidized linoleic acid metabolite-mediated peripheral inflammatory pain. Mol Pain. 2012;8:73. Epub 2012/09/26.

74. Sisignano M, Angioni C, Ferreiros N, Schuh CD, Suo J, Schreiber Y, et al. Synthesis of Lipid Mediators during UVB-Induced Inflammatory Hyperalgesia in Rats and Mice. PLoS One. 2013;8(12):e81228. Epub 2013/12/19. 
75. Janssen-Timmen U, Vickers PJ, Wittig U, Lehmann WD, Stark HJ, Fusenig NE, et al. Expression of 5-lipoxygenase in differentiating human skin keratinocytes. Proc Natl Acad Sci U S A. 1995;92(15):6966-70. Epub 1995/07/18.

76. Church MK, Griffiths TJ, Jeffery S, Ravell LC, Cowburn AS, Sampson AP, et al. Are cysteinyl leukotrienes involved in allergic responses in human skin? Clin Exp Allergy. 2002;32(7):1013-9. Epub 2002/07/09.

77. O'Flaherty JT, Thomas MJ, Lees CJ, McCall CE. Neutrophil-aggregating activity of monohydroxyeicosatetraenoic acids. Am J Pathol. 1981;104(1):55-62.

78. Cunningham FM, Wong E, Woollard PM, Greaves MW. The chemokinetic response of psoriatic and normal polymorphonuclear leukocytes to arachidonic acid lipoxygenase products. Arch Dermatol Res. 1986;278(4):270-3.

79. Ternowitz T, Andersen PH, Bjerring P, Fogh K, Schroder JM, Kragballe K. 15hydroxyeicosatetraenoic acid (15-HETE) specifically inhibits the LTB4-induced skin response. Arch Dermatol Res. 1989;281(6):401-5.

80. Fogh K, Sogaard H, Herlin T, Kragballe K. Improvement of psoriasis vulgaris after intralesional injections of 15-hydroxyeicosatetraenoic acid (15-HETE). J Am Acad Dermatol. 1988;18(2 Pt 1):279-85.

81. Kragballe K, Pinnamaneni G, Desjarlais L, Duell EA, Voorhees JJ. Dermis-derived 15-hydroxy-eicosatetraenoic acid inhibits epidermal 12-lipoxygenase activity. J Invest Dermatol. 1986;87(4):494-8.

82. Singh NK, Wang D, Kundumani-Sridharan V, Van Quyen D, Niu J, Rao GN. 15Lipoxygenase-1-enhanced Src-Janus kinase 2-signal transducer and activator of transcription 3 stimulation and monocyte chemoattractant protein-1 expression require redox-sensitive activation of epidermal growth factor receptor in vascular wall remodeling. $J$ Biol Chem. 2011;286(25):22478-88. Epub 2011/05/04.

83. Zhang G, Liu X, Wang C, Qu L, Deng J, Wang H, et al. Resolution of PMA-induced skin inflammation involves interaction of IFN-gamma and ALOX15. Mediators Inflamm. 2013;2013:930124.

84. Hong S, Alapure BV, Lu Y, Tian H, Wang Q. 12/15-Lipoxygenase deficiency reduces densities of mesenchymal stem cells in the dermis of wounded and unwounded skin. $\mathrm{Br} \mathrm{J}$ Dermatol. 2014;171(1):30-8.

85. Lu Y, Tian H, Hong S. Novel 14,21-dihydroxy-docosahexaenoic acids: structures, formation pathways, and enhancement of wound healing. J Lipid Res. 2010;51(5):923-32. Epub 2009/12/08.

86. Spector AA. Arachidonic acid cytochrome P450 epoxygenase pathway. J Lipid Res. 2009;50 Suppl:S52-6. Epub 2008/10/28.

87. Zeldin DC. Epoxygenase pathways of arachidonic acid metabolism. J Biol Chem. 2001;276(39):36059-62.

88. Konkel A, Schunck WH. Role of cytochrome P450 enzymes in the bioactivation of polyunsaturated fatty acids. Biochim Biophys Acta. 2011;1814(1):210-22. Epub 2010/09/28.

89. Supp DM, Hahn JM, McFarland KL, Combs KA, Lee KS, Inceoglu B, et al. Soluble epoxide hydrolase inhibition and epoxyeicosatrienoic acid treatment improve vascularization of engineered skin substitutes. Plast Reconstr Surg Glob Open. 2016;4(12):e1151.

90. Sander AL, Jakob H, Sommer K, Sadler C, Fleming I, Marzi I, et al. Cytochrome P450-derived epoxyeicosatrienoic acids accelerate wound epithelialization and neovascularization in the hairless mouse ear wound model. Langenbecks Arch Surg. 2011;396(8):1245-53. Epub 2011/09/03.

91. Moreno JJ. Cyclooxygenase and cytochrome P-450 pathways induced by fetal calf serum regulate wound closure in 3T6 fibroblast cultures through the effect of prostaglandin E2 and 12 and 20 hydroxyeicosatetraenoic acids. J Cell Physiol. 2003;195(1):92-8. Epub 2003/02/25.

92. Zhao H, Chen J, Chai J, Zhang Y, Yu C, Pan Z, et al. Cytochrome P450 (CYP) epoxygenases as potential targets in the management of impaired diabetic wound healing. Lab Invest. 2017. 
93. Ladd PA, Du L, Capdevila JH, Mernaugh R, Keeney DS. Epoxyeicosatrienoic acids activate transglutaminases in situ and induce cornification of epidermal keratinocytes. $\mathrm{J}$ Biol Chem. 2003;278(37):35184-92.

94. Chen L, Ackerman R, Guo AM. 20-HETE in neovascularization. Prostaglandins Other Lipid Mediat. 2012;98(3-4):63-8.

95. Guo AM, Arbab AS, Falck JR, Chen P, Edwards PA, Roman RJ, et al. Activation of vascular endothelial growth factor through reactive oxygen species mediates 20hydroxyeicosatetraenoic acid-induced endothelial cell proliferation. J Pharmacol Exp Ther. 2007;321(1):18-27.

96. Ohno Y, Nakamichi S, Ohkuni A, Kamiyama N, Naoe A, Tsujimura H, et al. Essential role of the cytochrome P450 CYP4F22 in the production of acylceramide, the key lipid for skin permeability barrier formation. Proc Natl Acad Sci U S A. 2015;112(25):7707-12.

97. Eilstein J, Lereaux G, Budimir N, Hussler G, Wilkinson S, Duche D. Comparison of xenobiotic metabolizing enzyme activities in ex vivo human skin and reconstructed human skin models from SkinEthic. Arch Toxicol. 2014;88(9):1681-94.

98. Baron JM, Wiederholt T, Heise R, Merk HF, Bickers DR. Expression and function of cytochrome p450-dependent enzymes in human skin cells. Curr Med Chem. 2008;15(22):2258-64.

99. Biro T, Toth BI, Hasko G, Paus R, Pacher P. The endocannabinoid system of the skin in health and disease: novel perspectives and therapeutic opportunities. Trends Pharmacol Sci. 2009;30(8):411-20.

100. Brown I, Cascio MG, Wahle KW, Smoum R, Mechoulam R, Ross RA, et al. Cannabinoid receptor-dependent and -independent anti-proliferative effects of omega-3 ethanolamides in androgen receptor-positive and -negative prostate cancer cell lines. Carcinogenesis. 2010;31(9):1584-91.

101. Movahed P, Jonsson BA, Birnir B, Wingstrand JA, Jorgensen TD, Ermund A, et al. Endogenous unsaturated $\mathrm{C} 18 \mathrm{~N}$-acylethanolamines are vanilloid receptor (TRPV1) agonists. J Biol Chem. 2005;280(46):38496-504.

102. Maccarrone M, Di Rienzo M, Battista N, Gasperi V, Guerrieri P, Rossi A, et al. The endocannabinoid system in human keratinocytes. Evidence that anandamide inhibits epidermal differentiation through CB1 receptor-dependent inhibition of protein kinase C, activation protein-1, and transglutaminase. J Biol Chem. 2003;278(36):33896-903.

103. Toth BI, Dobrosi N, Dajnoki A, Czifra G, Olah A, Szollosi AG, et al. Endocannabinoids modulate human epidermal keratinocyte proliferation and survival via the sequential engagement of cannabinoid receptor-1 and transient receptor potential vanilloid1. J Invest Dermatol. 2011;131(5):1095-104.

104. Kozono S, Matsuyama T, Biwasa KK, Kawahara K, Nakajima Y, Yoshimoto T, et al. Involvement of the endocannabinoid system in periodontal healing. Biochem Biophys Res Commun. 2010;394(4):928-33.

105. Wrobel A, Seltmann H, Fimmel S, Muller-Decker K, Tsukada M, Bogdanoff B, et al. Differentiation and apoptosis in human immortalized sebocytes. J Invest Dermatol. 2003;120(2):175-81. Epub 2003/01/25.

106. Dobrosi N, Toth BI, Nagy G, Dozsa A, Geczy T, Nagy L, et al. Endocannabinoids enhance lipid synthesis and apoptosis of human sebocytes via cannabinoid receptor-2mediated signaling. FASEB J. 2008;22(10):3685-95. Epub 2008/07/04.

107. Sugawara K, Biro T, Tsuruta D, Toth BI, Kromminga A, Zakany N, et al. Endocannabinoids limit excessive mast cell maturation and activation in human skin. $\mathrm{J}$ Allergy Clin Immunol. 2012;129(3):726-38 e8.

108. Lo Verme J, Fu J, Astarita G, La Rana G, Russo R, Calignano A, et al. The nuclear receptor peroxisome proliferator-activated receptor-alpha mediates the anti-inflammatory actions of palmitoylethanolamide. Mol Pharmacol. 2005;67(1):15-9.

109. Suardiaz M, Estivill-Torrus G, Goicoechea C, Bilbao A, Rodriguez de Fonseca F. Analgesic properties of oleoylethanolamide (OEA) in visceral and inflammatory pain. Pain. 2007;133(1-3):99-110. 
110. Petrosino S, Cristino L, Karsak M, Gaffal E, Ueda N, Tuting T, et al. Protective role of palmitoylethanolamide in contact allergic dermatitis. Allergy. 2010;65(6):698-711.

111. Ishida T, Nishiumi S, Tanahashi T, Yamasaki A, Yamazaki A, Akashi T, et al. Linoleoyl ethanolamide reduces lipopolysaccharide-induced inflammation in macrophages and ameliorates 2,4-dinitrofluorobenzene-induced contact dermatitis in mice. Eur $\mathrm{J}$ Pharmacol. 2013;699(1-3):6-13.

112. Balvers MG, Verhoeckx KC, Plastina P, Wortelboer HM, Meijerink J, Witkamp RF. Docosahexaenoic acid and eicosapentaenoic acid are converted by 3T3-L1 adipocytes to Nacyl ethanolamines with anti-inflammatory properties. Biochim Biophys Acta. 2010;1801(10):1107-14.

113. Figueroa JD, Cordero K, Serrano-Illan M, Almeyda A, Baldeosingh K, Almaguel FG, et al. Metabolomics uncovers dietary omega-3 fatty acid-derived metabolites implicated in anti-nociceptive responses after experimental spinal cord injury. Neuroscience. 2013;255:118.

114. Tosun NC, Gunduz O, Ulugol A. Attenuation of serotonin-induced itch responses by inhibition of endocannabinoid degradative enzymes, fatty acid amide hydrolase and monoacylglycerol lipase. J Neural Transm (Vienna). 2015;122(3):363-7.

115. Fonseca BM, Teixeira NA, Correia-da-Silva G. Cannabinoids as modulators of cell death: clinical applications and future directions. Rev Physiol Biochem Pharmacol. 2017.

116. Magina S, Esteves-Pinto C, Moura E, Serrao MP, Moura D, Petrosino S, et al. Inhibition of basal and ultraviolet B-induced melanogenesis by cannabinoid $\mathrm{CB}(1)$ receptors: a keratinocyte-dependent effect. Arch Dermatol Res. 2011;303(3):201-10.

117. Gegotek A, Biernacki M, Ambrozewicz E, Surazynski A, Wronski A, Skrzydlewska E. The cross-talk between electrophiles, antioxidant defence and the endocannabinoid system in fibroblasts and keratinocytes after UVA and UVB irradiation. J Dermatol Sci. 2016;81(2):107-17.

118. Berdyshev EV, Schmid PC, Dong Z, Schmid HH. Stress-induced generation of Nacylethanolamines in mouse epidermal JB6 P+ cells. Biochem J. 2000;346 Pt 2:369-74.

119. Felton SJ, Kendall AC, Almaedani AF, Urquhart P, Webb AR, Kift R, et al. Serum endocannabinoids and $\mathrm{N}$-acyl ethanolamines and the influence of simulated solar UVR exposure in humans in vivo. Photochem Photobiol Sci. 2017;16(4):564-74.

120. Kendall AC, Pilkington SM, Sassano G, Rhodes LE, Nicolaou A. N-Acyl ethanolamide and eicosanoid involvement in irritant dermatitis. $\mathrm{Br} J$ Dermatol. 2016;175(1):163-71.

121. Wohlman IM, Composto GM, Heck DE, Heindel ND, Lacey CJ, Guillon CD, et al. Mustard vesicants alter expression of the endocannabinoid system in mouse skin. Toxicol Appl Pharmacol. 2016;303:30-44.

122. Wright K, Rooney N, Feeney M, Tate J, Robertson D, Welham M, et al. Differential expression of cannabinoid receptors in the human colon: cannabinoids promote epithelial wound healing. Gastroenterology. 2005;129(2):437-53. 
Table 1: Examples of lipids and some of their roles in skin

\begin{tabular}{|c|c|}
\hline Lipid & Biological role \\
\hline Sapienic acid & Antimicrobial $(13,14)$ \\
\hline Oleic acid & Promotes keratinocyte proliferation (17) \\
\hline Palmitoleic acid & Promotes keratinocyte proliferation (18) \\
\hline Linoleic acid & Essential component of epidermal acylceramides (24) \\
\hline $\mathrm{PGE}_{2}$ & $\begin{array}{l}\text { Regulates fibroblast and keratinocyte growth }(34,36,37) \text {; recruitment of } \\
\text { immune cells }(40,41) \text {; vasodilation }(43) \text {; wound healing }(54-56) \text {; post- } \\
\text { inflammatory immune suppression (58) }\end{array}$ \\
\hline $\mathrm{PGE}_{1}$ & Recruitment of immune cells (43) \\
\hline $\mathrm{PGD}_{2}$ & Stimulates immune cell migration (48); hair loss (49) \\
\hline 9-HODE & Immune cell recruitment; pain (74) \\
\hline 13-HODE & Immune cell recruitment; pain (74) \\
\hline $\mathrm{LTB}_{4}$ & Immune cell recruitment (76) \\
\hline 12-HETE & Immune cell recruitment $(57)$ \\
\hline 15-HETE & $\begin{array}{l}\text { Suppresses inflammatory cytokine and lipid mediator production }(79,81,83) \text {; } \\
\text { vascular remodelling }(82)\end{array}$ \\
\hline 14-HDHA & Reepithelialisation (85); granulation (85); angiogenesis (85) \\
\hline EETs & $\begin{array}{l}\text { Vascularisation (89); epithelialisation (90, 91); angiogenesis (92); keratinocyte } \\
\text { cornification (93) }\end{array}$ \\
\hline AEA & $\begin{array}{l}\text { Inhibits fibroblast and keratinocyte proliferation (103, 104); suppresses mast } \\
\text { cell activation (107) }\end{array}$ \\
\hline PEA & Reduces itch (108); analgesic (108) \\
\hline OEA & Analgesic (109) \\
\hline LEA & Suppresses macrophage activation (111) \\
\hline EPEA & Reduces itch (112); analgesic (113) \\
\hline DHEA & Reduces itch (112); analgesic (113) \\
\hline
\end{tabular}




\section{FIGURE LEGEND}

Figure 1. Schematic outline of the main enzymatic reactions involved in the arachidonic acid cascade, showing the conversion of this polyunsaturated fatty acid to various classes of bioactive lipid mediators potentially important in cutaneous biology. Although the relevant enzymes are expressed in skin cells, not all mediators have been identified in human skin to date. AEA: arachidonoyl ethanolamine; COX: cyclooxygenase; CYP450: cytochrome P450; EET: epoxyeicosatrienoic acid; FAAH: fatty acid amide hydrolase; HETE: hydroxyeicosatetraenoic acid; 12-HETE-EA: 12-hydroxyeicosatetraenoic acid ethanolamine; LOX: lipoxygenase; $\mathrm{LXA}_{4}$ : lipoxin $\mathrm{A}_{4}$; NAPE-PLD: $\mathrm{N}$-acyl phosphatidylethanolamine phospholipase $\mathrm{D}$; NArPE: N-arachidonoyl phosphatidylethanolamine; $\mathrm{PC}$ : phosphatidylcholine; $\mathrm{PGE}_{2}$ : prostaglandin $\mathrm{E}_{2}$; $\mathrm{PGE}_{2}-\mathrm{EA}$ : prostaglandin $\mathrm{E}_{2}$ ethanolamine (prostamide); PLA 2 : phospholipase $\mathrm{A}_{2}$. 


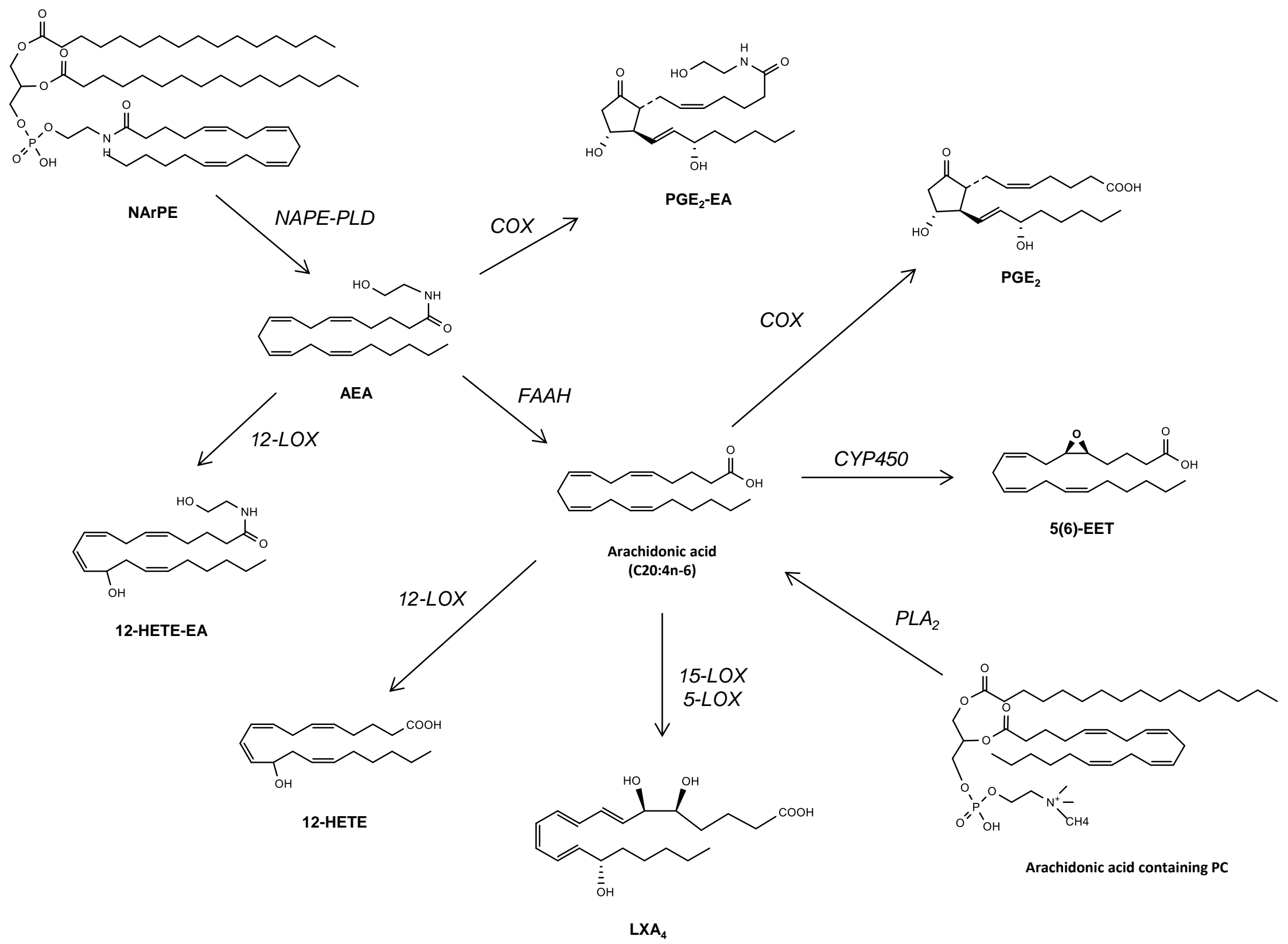

